National Marine

Fisheries Service

NOAA
Fishery Bulletin

a established in 1881 a
Spencer F. Baird

First U.S. Commissione of Fisheries and founder of Fishery Bulletin
Abstract-Recently, it has been suggested that spiny dogfish (Squalus acanthias) in the western North Atlantic Ocean have a shorter gestation period than the widely cited 2 years, have an asynchronous reproductive cycle, and carry pups in various stages of development. Mature female spiny dogfish were collected monthly from July 2013 through June 2015 to confirm gestation period and pupping seasonality off southern New England, and data on 2545 embryos from 622 females were obtained. Recent postpartum females and females with candled embryos appeared from January through April indicating parturition that was followed closely by mating. Vitellogenesis is concurrent with embryo growth, and therefore ova are ready for fertilization immediately after pupping. Visible embryos were observed in June, and growth continued until the external and internal yolks were absorbed and the umbilical scar was partially healed. Gestation period was approximately 23 months. No individual was observed with first and second year embryos. Average fecundity per female was estimated on the basis of the largest group of oocytes (5.3), free-living embryos (4.3), and total embryos (candled and free-living) (4.5). These values are similar to those of previous studies, but average fecundity by maternal size class has decreased from that of previous studies and is negatively correlated with spawning stock biomass, which provides supporting evidence for density dependent fecundity.

Manuscript submitted 30 September 2016. Manuscript accepted 24 July 2017.

Fish. Bull. 115:473-483 (2017).

Online publication date: 8 August 2017. doi: 10.7755/FB.115.4.4

The views and opinions expressed or implied in this article are those of the author (or authors) and do not necessarily reflect the position of the National Marine Fisheries Service, NOAA.

\title{
Gestation period and pupping seasonality of female spiny dogfish (Squalus acanthias) off southern New England
}

\author{
Lisa J. Natanson (contact author) ${ }^{1}$ \\ Camilla T. McCandless ${ }^{1}$ \\ Kelsey James ${ }^{2}$ \\ John Hoey ${ }^{1}$ \\ Email address for contact author: lisa.natanson@noaa.gov \\ ${ }^{1}$ Northeast Fisheries Science Center \\ National Marine Fisheries Service, NOAA \\ 28 Tarzwell Drive \\ Narragansett, Rhode Island 02882 \\ 2 Department of Biological Sciences \\ University of Rhode Island \\ 120 Flagg Road \\ Kingston, Rhode Island 02881
}

Spiny dogfish (Squalus acanthias) occur in the western North Atlantic (WNA) Ocean from Labrador, Canada, to Florida, United States, but are most abundant from Nova Scotia, Canada, to Cape Hatteras, North Carolina (Collette and KleinMacPhee, 2002). Seasonal migrations occur northward in the spring and summer and southward in the fall and winter (Hisaw and Albert, 1947; Jensen, 1965; McMillan and Morse, 1999). Conventional and satellite tagging studies also suggest some localized movement occurs within these large-scale seasonal migrations, for instance, a southern and a northern group overlap in the Gulf of Maine (Campana et al. ${ }^{1}$; and

${ }^{1}$ Campana, S. E., A. J. F. Gibson, L. Marks, W. Joyce, R. Rulifson, and M. Dadswell. 2007. Stock structure, life history, fishery and abundance indices for spiny dogfish (Squalus acanthias) in Atlantic Canada. Canadian Science Advisory Secretariat, Res. Doc. 2007/089, 133 p. [Available from website.] references within) and off southern New England (SNE) (Carlson et al., 2014).

The fishery on mature female spiny dogfish in the 1990 s led to a significant reduction in female spawning stock biomass in the WNA (Rago and Sosebee, 2009), because the resulting size-selective mortality exceeded the growth and reproductive rates of this $K$-selected species. Additionally, the size at first maturity for female spiny dogfish declined by $10 \mathrm{~cm}$ in length between the late 1980 s and the late 1990s and may have been a result of this reduction in female spawning stock biomass (Sosebee, 2005). However, the size-selective nature of the fishery left the abundance of the generally smaller male spiny dogfish relatively unaffected (Rago and Sosebee, 2009). Recent updates on the status of spiny dogfish show that the female spawning stock biomass has been rebuilt, the population is no longer overfished, and overfishing is not oc- 
curring (Rago and Sosebee ${ }^{2,3}$ ). Sustainability of this fishery is directly linked to the reproduction of adult females and an overabundance of males may, in fact, be detrimental to recruitment (Rago ${ }^{4}$ ). Despite success in rebuilding the female spawning stock biomass and the increased efficiency in use of the resource (a decrease in the ratio of discards to landings), spiny dogfish management still faces many challenges.

Numerous studies have been conducted on the reproduction of the spiny dogfish worldwide (Kaganovskaia, 1937; Yamamoto and Kibezaki, 1950; Jensen, 1965; Ketchen, 1972; Hanchet, 1988; Avsar, 2001; Chatzispyrou and Megalofonou, 2005; Di Giacomo et al., 2009; Capapé and Reynaud, 2011; Gračan et al., 2013). Studies specific to the WNA have suggested that there is an 18-25 month gestation period, which may depend on water temperature (Templeman, 1944; Hisaw and Albert, 1947; Bigelow and Schroeder, 1953; Nammack et al., 1985; Campana et al., 2009; Bubley, 2010, Bubley et al., 2013). Although these reports all suggest a similar gestation period, in most cases the time periods over which the research was conducted were not adequate to fully support these conclusions. Many of these studies were dependent either on samples that were collected over only a few months or on sporadic partial-year sampling (Templeman, 1944; Hisaw and Albert, 1947; Nammack et al., 1985; Campana et al., 2009). Nammack et al. (1985); for example, data were collected between Cape Fear, North Carolina, and the Gulf of Maine between November and May to characterize the reproduction of the spiny dogfish off the northeastern United States. Furthermore, these studies suggested a similar pattern for the gestation period that had been described by Jones and Geen (1977) for spiny dogfish in the Pacific Ocean, a species that has now been identified as a separate species with different life history parameters: the Pacific spiny dogfish (Squalus suckleyi) (Campana et al., 2006; Ebert, 2010). More recently, Campana et al. (2009) described a 2-year gestation period for spiny dogfish in the WNA off of the Eastern Coast of Canada, however, as in other studies, this conclusion was based on limited sampling between June and October. Nevertheless, a 2-year gestation period is currently used in the stock assessment process for WNA spiny dogfish. Studies of shark reproduction, in general, have shown substantial latitudinal variation, as well as mixed gestational periodicity in a species in the same area (Driggers and Hoffmayer, 2009; Hoffmayer et al., 2013; Taylor et al.,

\footnotetext{
2 Rago, P., and K. Sosebee. 2014. Update of landings and discards of spiny dogfish in 2014, 19 p. [Available from the Mid-Atlantic Fishery Management Council, 800 North State St., Ste. 201, Dover, DE 19901.]

${ }^{3}$ Rago, P., and K. Sosebee. 2015. Update on the status of spiny dogfish in 2015 and projected harvest at the Fmsy proxy and Pstar of 40\%, 65 p. Mid-Atlantic Fishery Management Council, Dover, DE. [Available from website.]

${ }^{4}$ Rago, P. 2015. Spiny dogfish: New England's favorite species. Presentation for the Cape Cod Commercial Fisherman's Alliance in Chatham, MA, on 2 March 2015. [Available from website, accessed October 2015.]
}

2016). In particular, it has been suggested that there are regional differences in the reproductive cycles in the WNA spiny dogfish population (Sulikowski et al. ${ }^{5}$ ). Specifically these authors suggest that regional asynchronies in reproductive biology exist and that there is the need for regional sampling and detailed examination of the reproductive state of spiny dogfish for comparative purposes.

Because of the significance of female reproduction for the sustainability of the WNA spiny dogfish fishery and because of new data on the plasticity and latitudinal variations in other elasmobranchs (Driggers and Hoffmayer, 2009; Taylor et al., 2016), more information specific to this stock in each region is required to determine whether latitudinal plasticity exists and to ensure accurate assessments and reliable projections that lead to more sustainable management practices. An intensive sampling regimen was initiated to obtain detailed life history data as part of the Cooperative Research Program of the National Marine Fisheries Service's (NMFS). We report on one portion of this study, specifically, the gestation period and pupping seasonality of mature female spiny dogfish off SNE between Massachusetts and Rhode Island and in the mid-Atlantic off the coast of New Jersey. We address a lack of adequate data on reproductive characteristics in this region and revisit fecundity at maternal length to evaluate any density-dependent effects that may have occurred as the female spawning stock biomass was rebuilding.

\section{Materials and methods}

An attempt was made to collect a minimum of 30 mature female spiny dogfish greater than or equal to $50 \%$ maturity (which was estimated at $75 \mathrm{~cm}$ in stretched total length, STL] [66.1 cm fork length, FL] [Bubley, 2010]), per month for 2 years from July 2013 through July 2015. Female spiny dogfish were requisitioned from commercial fishing vessels fishing primarily off SNE between Massachusetts and Rhode Island but some sampling occurred off the coast of New Jersey through the NMFS Cooperative Research Program. Sampling location and date were noted and the samples were frozen. If sample length was $<75 \mathrm{~cm}$ STL and the sample was mature it was included in the study.

Fork, total, and stretched total lengths were measured over the body (FL: from the tip of the snout to the fork in the tail; TL: from the tip of the snout to a point on the horizontal axis intersecting a perpendicular line extending downward from the tip of the upper caudal lobe to form a right angle; and STL: from

\footnotetext{
${ }^{5}$ Sulikowski, J., B. Galuardi, W. Bubley, W. Driggers III, E. Hoffmayer, A. Cicia, A. Carlson, and P. Tsang. 2010. Dismissing dogma? What do we really know about the spiny dogfish, Squalus acanthias, population in the U.S. western north Atlantic Ocean. ICES CM 2010/E:16, 8 p. [Available from website.]
} 
the tip of the snout to the upper lobe of the caudal fin pulled downward to align with the body) to the nearest millimeter on each specimen. A girth measurement was taken behind the pectoral fins of each specimen. Each fish was weighed to the nearest tenth of a kilogram.

After external measurements were taken, an incision was made from the cloaca through the pectoral girdle along the ventral surface to retract the belly flap and expose the abdominal cavity. Organ terms follow those of Hamlett and Koob (1999). Both sides of the female spiny dogfish reproductive tract are functional; therefore, both sides of each specimen were dissected and measured. Measurements were taken to the nearest millimeter and weights to the nearest tenth of a gram in the following order: ovary weight, diameter of each of the largest group of oocytes and at least 1 of the next size group. In pregnant females, all embryos were measured (FL and STL, in centimeters along a straight line), weighed (in grams) (without external yolk which was weighed separately [in grams]) and visually examined for developmental stage of the litter (i.e., according to the condition of the umbilical scar). If there was no external yolk, the embryo was weighed and the internal yolk was removed and weighed (in grams). Litter sizes and sex of an embryo were also recorded. In many cases it was clear that pups had been aborted before dissection and these instances were noted. Developmental stages were the following: mature ovarian oocyte, candled embryo (embryo and yolk covered by a membranous envelope (stage 1 in Hisaw and Albert, 1947), free-living embryo (no longer candled), embryo with external yolk, and embryo with no eternal yolk and with healing umbilical scars.

\section{Fecundity}

Three estimates of fecundity were calculated: 1) by counting the number of oocytes in the largest group of oocytes in the ovaries, which were presumed to be the next litter; 2) by using total embryo count (candled and free-living embryos), and 3) by using counts of only free-living embryos. Mean number of all 3 indices per female were plotted against maternal size. Additionally, the data were presented by $5-\mathrm{cm}$ maternal size increments for comparison with data from previous studies. Fecundity measures for each 5 -cm maternal size class and female spawning stock biomass, estimated by using a 3-point moving average (Rago and Sosebee ${ }^{3}$ ), were plotted over time to determine potential signs of density dependence. Fecundity data from 1998 through 2002 were obtained from Sosebee (2005) and data from 2006 to 2009 were obtained from Bubley (2010). Data summaries that included only averages across years were plotted at the midpoint of the time series. Additionally, correlation analyses were conducted to determine correlations between the mean fecundity of each 5-cm maternal size class and spawning stock biomass (SSB), estimated by using a 3-point moving average (Rago and Sosebee ${ }^{3}$ ), and with relative abundance estimates based on mean number of mature females caught per tow during the NOAA Northeast Fisheries Science Center spring bottom-trawl survey (Silva, 1993).

\section{Reproductive seasonality}

Gestation period was determined by plotting the size of the embryos over time, assuming samples were from the same stock. The concurrent increase in follicle size with embryo size (see the Results section) also allows one to infer the mating period on the basis of the increase of follicle size in the ovaries followed by a sudden decrease and presence of fertilized eggs in the uterus. Each shark was also examined for evidence of mating scars.

\section{Size of full-term embryos}

The determination of the size that the embryos were considered full term was based on observation of umbilical scars, size of internal yolks, and maximum sizes of embryos in relation to minimum sizes of free-living swimming individuals. These data were confounded by the differences in size of term embryos in relation to maternal size (see the Results section).

\section{Results}

Between July 2013 and June 2015, 622 mature female dogfish ranging in size from 75.3 to $104.2 \mathrm{~cm}$ STL (mean $88.5 \mathrm{~cm}$ STL; 66.8-94.5 cm FL [mean 79.2 $\mathrm{cm} \mathrm{FL])} \mathrm{were} \mathrm{sampled.} \mathrm{Between} \mathrm{July} 2013$ and June 2014, spiny dogfish were obtained from SNE between Massachusetts and Rhode Island in all months, except October, when a federal government furlough precluded sampling (Table 1, Fig. 1). Between July 2014 and June 2015 , samples were obtained in in this region in 6 out of 12 months (Table 1). In October and December 2014 samples were obtained from off shore of New Jersey in an attempt to maintain the monthly sampling time series. No samples were available during September 2014 and March and May 2015 as a result of the establishment of a gear-restricted area as an accountability measure for windowpane (Scophthalmus aquosus) in 2014 and 2015 (GARFO ${ }^{6,7}$ ). This measure restricted fishing in the areas where spiny dogfish are

\footnotetext{
${ }^{6}$ GARFO (Greater Atlantic Regional Fisheries Office). 2014. Greater Atlantic Region Bulletin. Northeast multispecies common pool fishery fishing year 2014 regulations, $7 \mathrm{p}$. Greater Atlantic Regional Fisheries Office, NOAA, Gloucester, MA. [Available from website.]

${ }^{7}$ GARFO (Greater Atlantic Regional Fisheries Office). 2015. Greater Atlantic Region Bulletin. Groundfish fishermen: NOAA Fisheries approves Framework 52 to the Groundfish Plan-southern windowpane flounder restricted gear area reduced in size, 3 p. Greater Atlantic Regional Fisheries Office, Greater Atlantic Regional Fisheries Office, NOAA Gloucester, MA. [Available from website.]
} 
Table 1

Locations, numbers, and dates of sampling of female spiny dogfish (Squalus acanthias) off southern New England, between Massachusetts and Rhode Island, and off New Jersey from July 2013 to July 2015.

\begin{tabular}{|c|c|c|c|c|c|}
\hline Month/Year & General location & Date & Latitude $\left(\mathrm{N}^{\circ}\right)$ & Longitude $\left(\mathrm{W}^{\circ}\right)$ & $\begin{array}{c}\text { No. of } \\
\text { samples }\end{array}$ \\
\hline July 2013 & Southern New England & $7 / 9 / 2013$ & 4104.47 & 7137.01 & 30 \\
\hline \multirow[t]{2}{*}{ August 2013} & Southern New England & $8 / 21 / 2013$ & 4108.18 & 7119.16 & 19 \\
\hline & Southern New England & $8 / 29 / 2013$ & 4103.44 & 7129.24 & 11 \\
\hline September 2013 & Southern New England & 9/11/2013 & 4102.58 & 7123.01 & 28 \\
\hline October 2013 & No samples & & & & \\
\hline November 2013 & Southern New England & $11 / 5 / 2013$ & 4100.44 & 7133.70 & 30 \\
\hline December 2013 & Southern New England & $12 / 8 / 2013$ & 4054.55 & 7130.94 & 30 \\
\hline January 2014 & Southern New England & $1 / 29 / 2014$ & 4057.56 & 7116.28 & 30 \\
\hline \multirow[t]{2}{*}{ February 2014} & Southern New England & $2 / 9 / 2014$ & 4019.61 & 7117.72 & 23 \\
\hline & Southern New England & $2 / 26 / 2014$ & 4106.54 & 7120.69 & 7 \\
\hline \multirow[t]{2}{*}{ March 2014} & Southern New England & $3 / 25 / 2014$ & 4049.07 & 7131.32 & 6 \\
\hline & Southern New England & $3 / 24 / 2014$ & 4035.88 & 7123.47 & 8 \\
\hline \multirow{2}{*}{ April 2014} & Southern New England & $4 / 21 / 2014$ & 4054.08 & 7132.74 & 30 \\
\hline & Southern New England & $4 / 22 / 2014$ & 4100.00 & 7135.00 & 31 \\
\hline May 2014 & Southern New England & $5 / 27 / 2014$ & 4113.66 & 7129.06 & 31 \\
\hline \multirow[t]{2}{*}{ June 2014} & Southern New England & $6 / 17 / 2014$ & 4116.11 & 7127.14 & 42 \\
\hline & Southern New England & & 4116.00 & 7143.00 & \\
\hline \multirow[t]{2}{*}{ July 2014} & Southern New England & $7 / 8 / 2014$ & 4113.48 & 7128.45 & 12 \\
\hline & Southern New England & $7 / 25 / 2014$ & 4100.40 & 7133.97 & 17 \\
\hline \multirow[t]{2}{*}{ August 2014} & Southern New England & $8 / 26 / 2014$ & 4100.12 & 7137.83 & 14 \\
\hline & & $8 / 25 / 2014$ & 4100.12 & 7137.00 & 16 \\
\hline September 2014 & No samples & & & & \\
\hline October 2014 & New Jersey & $10 / 29 / 2014$ & 3947.43 & 7358.87 & 30 \\
\hline November 2014 & Southern New England & $11 / 4 / 2014$ & 4116.68 & 7124.79 & 29 \\
\hline December 2014 & New Jersey & $12 / 11 / 2014$ & 3950.00 & 7401.00 & 30 \\
\hline January 2015 & Southern New England & $1 / 14 / 2015$ & 4059.24 & 7113.29 & 31 \\
\hline February 2015 & Southern New England & $2 / 4 / 2015$ & 4051.59 & 7132.05 & 28 \\
\hline March 2015 & No samples & & & & \\
\hline April 2015 & Southern New England & $4 / 7 / 2015$ & 4036.22 & 7149.37 & 32 \\
\hline May 2015 & No samples & & & & \\
\hline \multirow[t]{2}{*}{ June 2015} & Southern New England & $6 / 5 / 2015$ & 4113.45 & 7141.31 & 14 \\
\hline & Southern New England & $6 / 4 / 2015$ & 4114.30 & 7139.00 & 13 \\
\hline
\end{tabular}

traditionally caught (Fig. 1). Quantity, date, and location of sampling varied owing to fishing activity.

\section{Fecundity and litter characteristics}

Most spiny dogfish $(n=551)$ contained embryos in the uteri. Of the samples without embryos $(n=71), 64$ were caught between January and April and all but 2 of these fish had mature ovarian follicles that were ready for ovulation. Those 2 females appeared to be maturing for the following mating season. Of the 7 remaining individuals: 4 appeared to have pupped owing to stress, 2 appeared to be maturing, and it could not be determined why the last individual did not have pups. A bimodal distribution of embryo sizes was observed in most months of sampling and indicated that some females were in the first year of gestation, while some were in the second year. In no case were candled (first year) and free-living (second year) embryos found in the same individual; therefore only 1 set of developing embryos was observed per female.

A total of 2545 embryos, ranging in size from nonvisible candled to term ( $30.8 \mathrm{~cm}$ STL), were examined. Of these, 1447 embryos were developed sufficiently for sex determination. Although individual litters were commonly seen to be predominantly of one sex, the overall sex ratio was 1:1 (733 female, and 714 male). Candled embryos were visible to the naked eye in June and had an average size of $0.21 \mathrm{~cm}$ STL and by November they averaged $6 \mathrm{~cm}$ STL. Embryos averaged $19 \mathrm{~cm}$ STL by the following June.

Fecundity was estimated by the number of developing embryos in the uteri and the number of developing oocytes in the ovaries. Many of the dogfish, regardless of the stage of gestation, appeared to lose embryos before dissection. Evidence for this consisted in observations of pups being partially extruded through the clo- 


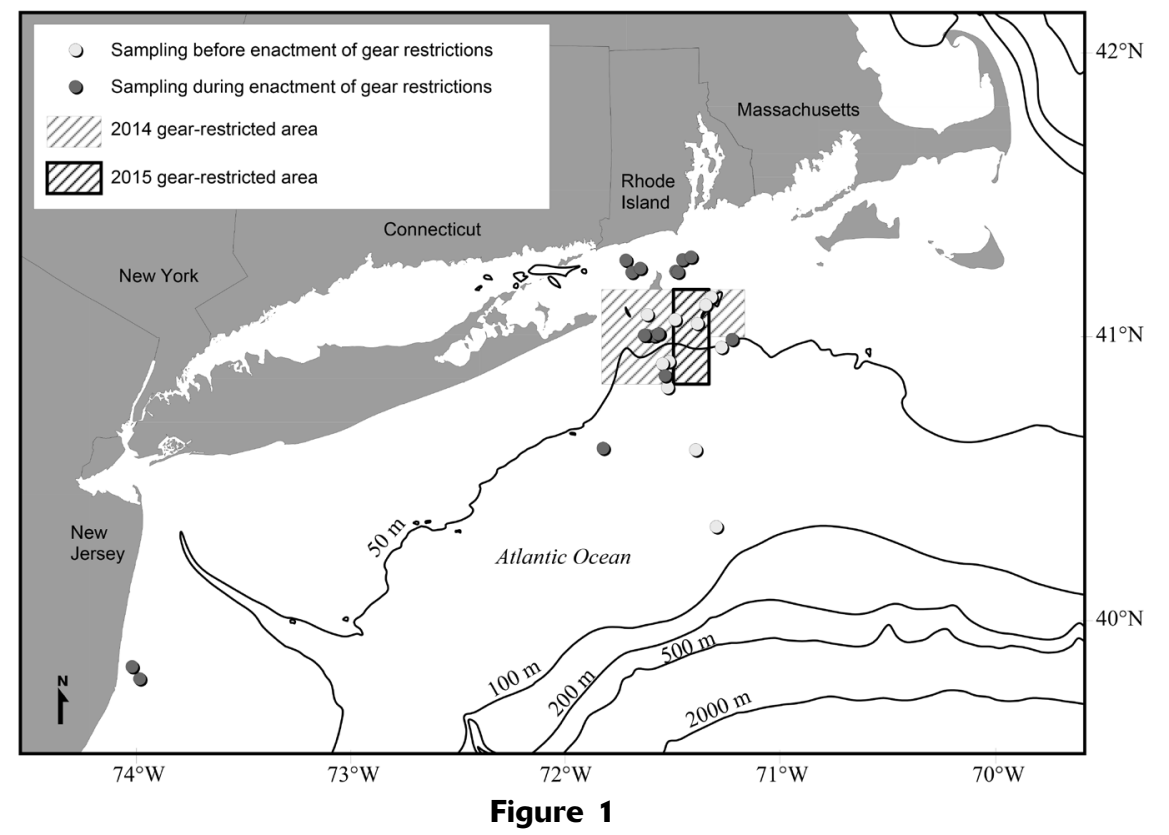

Map of locations where spiny dogfish (Squalus acanthias) were sampled off southern New England, between Massachusetts and Rhode Island, and off New Jersey from July 2013 to July 2015. A gear-restricted area was established as an accountability measure for windowpane (Scophthalmus aquosus) in 2014 and 2015 .

aca, of extra pups in the bottoms of the bags containing the samples, and of partly flaccid uteri, with or without 1 or more embryos. For these reasons the number of free-living embryos per female is a biased (and probably low) estimate of fecundity, whereas the number of developing oocytes of the largest group of developing oocytes in the ovaries may be an upper estimate, some may ultimately not have been fertilized. The number of embryos per female was calculated both with total embryos (free-living and candled litters: mean=4.5 embryos, range $=1-11$ embryos, $n=542$ ) and with free-living embryos only (mean $=4.3$ embryos, range $=1-9$ embryos; $n=338$ ) for comparison with results of other publications (Table 2). Because of the similarity in these es- timates, total embryos were used in relation to female size classes. The number of maturing oocytes for the next litter was difficult to discern in newly mated females; therefore the fecundity estimates based on number of developing oocytes were taken only from females with visible embryos (mean $=5.3$ embryos, range $=1-10$ embryos; $n=443$ ).

The mean values from all 3 types of fecundity estimates (developing oocytes, total embryos, and freeliving (only) embryos) indicate a significant $(P<0.0001)$ positive relationship between litter size and maternal size (Fig. 2, A-C). This increase in litter size with maternal size is also evident when the total and free-living embryo data are broken down into 5-cm STL size

\section{Table 2}

Mean number of free-living and total embryos per female spiny dogfish (Squalus acanthias) and sample size for each size class of females, defined by 5 -cm intervals of stretched total length in centimeters. Values for total embryos (candled and free-living embryos combined) are given in parentheses.

\begin{tabular}{cccc}
\hline Size class $(\mathrm{cm})$ & Mean & Standard deviation & Sample size \\
\hline $75-79$ & $2.25(3.25)$ & $1.50(1.58)$ & $4(8)$ \\
$80-84$ & $3.26(3.45)$ & $1.29(1.31)$ & $57(95)$ \\
$85-89$ & $4.08(4.23)$ & $1.32(1.31)$ & $136(203)$ \\
$90-94$ & $4.89(5.11)$ & $1.33(1.31)$ & $114(184)$ \\
$95-99$ & $4.70(5.20)$ & $2.20(2.19)$ & $20(40)$ \\
$100-104$ & $6.00(6.33)$ & $2.38(2.84)$ & $7(12)$ \\
All size classes & $4.27(4.50)$ & $1.55(1.59)$ & $338(542)$ \\
& & &
\end{tabular}




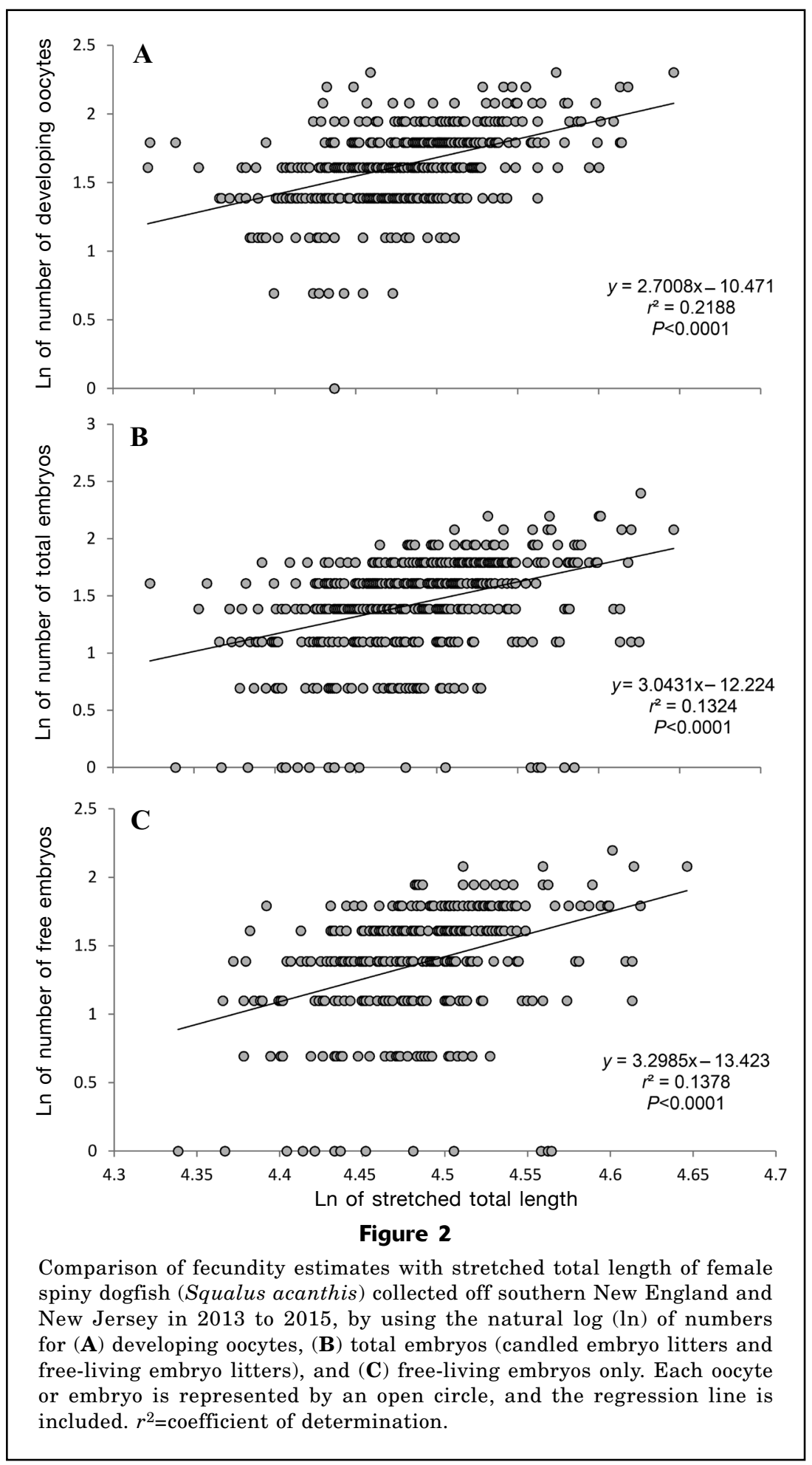

classes (Table 2). The only exception is the $95-99 \mathrm{~cm}$ STL size class for free-living embryos, which shows a decrease from the previous size class; however, the mean number nearly triples for free-living embryos and nearly doubles for total embryos from the smallest to the largest size class (Table 2). A plot showing fecundity by size class and female spawning stock bio- mass over time reveals a divergent pattern between fecundity and biomass during the 2000s (Fig. 3). Correlation analyses indicate negative correlations between female spawning stock biomass and fecundity for each size class, although significant correlations were found only within the smallest (80-84 cm STL) and largest (95-99 cm STL) size classes analyzed (Fig. 4). Analy- 


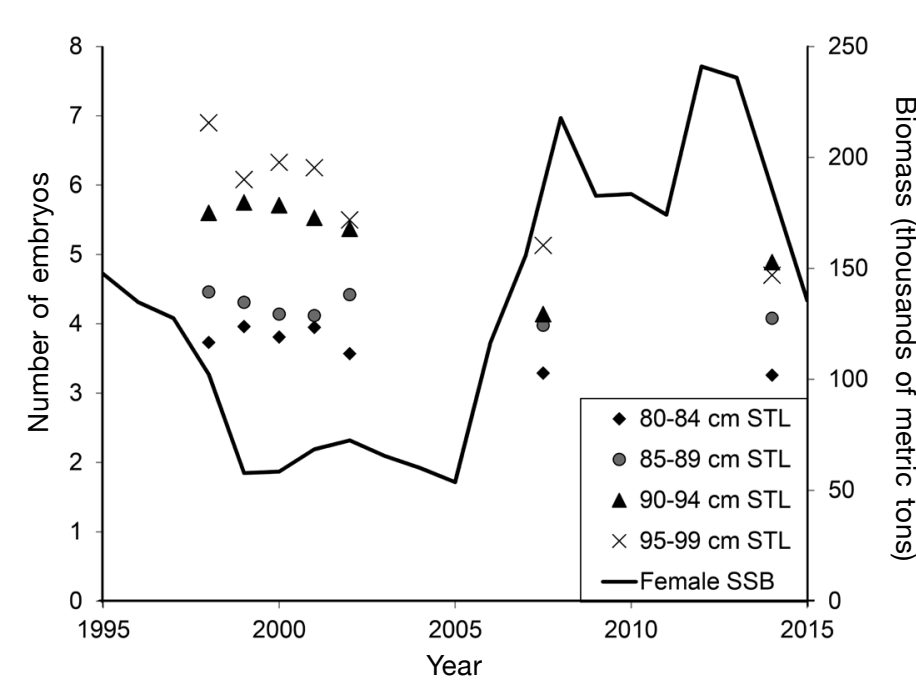

Figure 3

Mean fecundity of females by maternal size class, defined in 5 -cm increments of stretched total length (STL), and female spawning stock biomass (SSB), estimated by using a 3-point moving average (Rago and Sosebee ${ }^{3}$ ), for catch of spiny dogfish (Squalus acanthias) from the NOAA Northeast Fisheries Science Center spring bottom trawl survey, plotted over time. Fecundity data from 1998 to 2002 were obtained from Sosebee (2005), an average from 2006 to 2009 was obtained from Bubley (2010), and an average from 2013 to 2015 was obtained from this study. the data collected in July 2013 (month 7) with candled embryos, to illustrate the entire 2-year growth cycle during gestation, with the result showing growth from fertilization (month 1) through birth (month 23; Fig. 5A). Moreover, the decrease in external yolk size is plotted to show the use of the yolk during growth. Assuming that those oocytes that are fertilized first are pupped first, one can calculate the gestation period as 23 months: mating first occurs in January and parturition possibly as early as December, 23 months later.

Data plotted by using the mean weight of the ovaries during the growth period of these same fish show a concurrent increase in ovary size during gestation (Fig. 5B). The data from January 2014 were limited $(n=4)$ but indicated a drastic decrease in ovary size followed by an increase that is most likely an artifact of the small sample size. Together, these data suggest a 2-year synchronous growth cycle such that once the embryos are pupped, the female is ready to mate again. This is further supported by the observation of a short period where females had flaccid empty uteri followed immediately by females with candled embryos. The lack of any significant number of mature nongravid females at any other time of the year also supports this conclusion.

\section{Size of full-term embryos}

ses with the use of relative abundance estimates also showed negative correlations between abundance and fecundity for each size class. Significant correlations with the use of relative abundance were found only for the 90-95 cm STL size class during the 2000s (Fig. 4).

\section{Reproductive seasonality}

The shift from a predominance of large full-term embryos, to empty uteri, and then candled embryos in the uteri took place between January and April. The first females with flaccid, empty uteri were caught in January of both 2014 and 2015, and the first females with candled embryos were caught in February of 2014 and January of 2015. The occurrence of both these stages and the observation of full-term pups proceeded through at least April of both years, after which all females were either in the first or second year of gestation. These data suggest that protracted pupping and subsequent mating take place between January and April, possibly extending from late December to early May, although embryo development among individuals is synchronous during the rest of the year. No mating scars were observed at any time of the year to corroborate or refute mating periodicity. On the basis of these data, we plotted growth of the embryos starting in January (month 1) as the first month of possible fertilization. We used data gathered for newly mated females from February through June of 2014 (months 2-6) plotted in front of
The lack of an external yolk sac was not a decisive indicator of the terminal stage of embryonic development because litters were observed with no external yolks. Additionally, embryos were found with no internal yolk and they had healing or healed umbilical scars, indicating that term embryos would have no internal or external yolks. Full-term embryos (no internal yolk) ranged in size from 22.0 to $30.8 \mathrm{~cm}$ STL. The smallest mean litter size with no external yolks and healed umbilical scars was $20.2 \mathrm{~cm}$ STL (from a 77.6-cm-FL female); the average weight of the internal yolks was $1.3 \mathrm{~g}$ and this litter was caught at the end of October. The largest mean size of pups in a litter was 30.5 cm STL (78.4 cm FL). These embryos were observed at the beginning of April, had no external or internal yolks, and they had healing umbilical scars. The data indicate that a full-term embryo has a mostly healed umbilical scar and no internal or external yolk.

With this study, we confirm that spiny dogfish have a 2-year reproductive period in the region off SNE between Massachusetts and Rhode Island. Our data indicate that these spiny dogfish have at least a 23-month gestation period, which we determined by following the development of a group of embryos from candled em-

\section{Discussion}




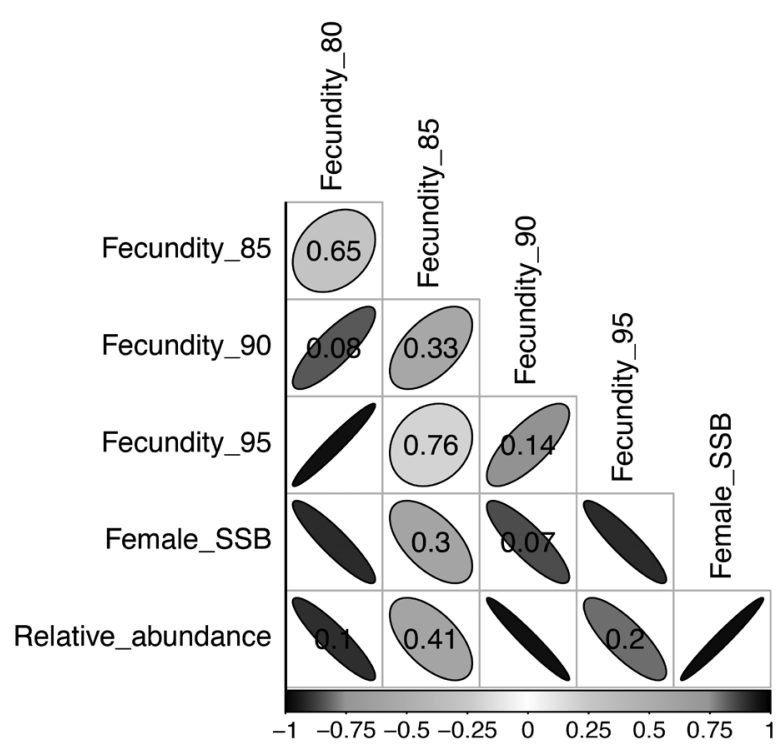

Figure 4

Correlation matrix of fecundity and abundance trends of spiny dogfish (Squalus acanthias) during 2000-2015. Mean fecundity of females by maternal size class, defined in 5-cm increments of stretched total length, is correlated with spawning stock biomass (SSB), estimated by using a 3-point moving average (Rago and Sosebee ${ }^{3}$ ), and with relative abundance estimates based on mean number of mature females caught per tow during the NOAA Northeast Fisheries Science Center spring bottom-trawl survey (Silva, 1993). Fecundity for the 4 maternal size classes, 80-84, 85-89, 90-94, and $95-99 \mathrm{~cm}$ in stretched total length, are labeled as Fecundity_80, Fecundity_85, Fecundity_90, and Fecundity_95, respectively. Numerical values denote $P$-values for nonsignificant correlations at an alpha level of 0.05. Fecundity data from 2000 to 2002 were obtained from Sosebee (2005), data from 2006 to 2009 were obtained from Bubley (2010), and data from 2013 to 2015 came from this study.

bryos to parturition. This gestation period is slightly longer than that found by Hisaw and Albert (1947; 20-22 months), slightly shorter than that reported by Templeman (1944; 24 months), and similar to that described by Bubley (2010; 22-23 months).

We found a large range in the sizes of ova ready for fertilization and a corresponding large size range of full-term pups. This was also observed in other studies and it has been suggested that larger ovarian eggs have a larger supply of yolk and would grow into larger embryos and would remain in the uterus longer than smaller eggs (Ford, 1921; Templeman, 1944; Hisaw and Albert, 1947). The embryonic growth rate that we observed was similar to that proposed by Campana et al. (2009) and Henderson et al. (2002), that is slow growth during the first few months followed by faster growth in July through October. Campana et al. (2009) found approximately 3 -cm-TL embryos by October in year 1 , and although we are missing October data, our November average was $6 \mathrm{~cm}$ STL. By the following June, their samples were approximately $16 \mathrm{~cm} \mathrm{FL}$ and those from the current study averaged $19 \mathrm{~cm}$ STL $(17.0 \mathrm{~cm}$ FL). Our results were similar to those of Henderson et al. (2002) who observed candled embryos in December through July. The size of full-term embryos in our investigation ranged from 19.7 to $30.8 \mathrm{~cm}$ STL, which is again similar to results of full-term and near-term size estimates from other studies in the WNA (Templeman, 1944; Hisaw and Albert, 1947; Nammack et al., 1985). Although many similar size embryos were found with internal yolk sacs, they did not appear ready for natural parturition. The observation of litters with full-term-size individuals and no internal yolks suggests that the internal yolk is consumed before parturition. This suggestion is in contrast to the suggestion by Jones and Geen (1977) that the internal yolk is maintained for 2 months past parturition.

Our data show that parturition is followed closely by ovulation and mating and all of these events occur between January and April, although most commonly from February through March. This time frame is longer than previously proposed for this geographic area (Hisaw and Albert, 1947) and is also different from that found in the Gulf of Maine by Bubley (2010), who reported parturition before January (October-December) followed closely by fertilization. Additionally, Campana et al. (2009) found similar results off eastern Canada with a 22-24 month gestation period, pupping from January through March, and fertilization immediately after pupping. The timing of parturition observed in our study is further corroborated by the finding of large numbers of neonate spiny dogfish in February off Block Island, Rhode Island, close to our sampling area (Sulikowski et al., 2013).

Studies have shown that there is a greater plasticity in elasmobranch reproduction than previously thought (Driggers and Hoffmayer, 2009), although the results from studies of dogfish throughout the WNA are reasonably consistent. There may be latitudinal differences. Bubley (2010), for example, reported results from the Gulf of Maine that are approximately 1 month earlier than those that we found for SNE between Massachusetts and Rhode Island. Essentially all the regional studies of spiny dogfish in the WNA have a similar gestation period and have only slightly offset mating and parturition times. The variation in all these studies could be due to latitude or plasticity of the reproductive cycle of this species, and could be potentially related to environmental conditions. More regional studies on spiny dogfish and elasmobranchs in general are required to determine whether differences observed are truly specific to a region or are due to plasticity or size (or both), or age of the female (Lombardi-Carlson et al., 2003; Driggers and Hoffmayer, 2009; Hoffmayer et al., 2013; Rochowski et al., 2015; Taylor et al., 2016).

The average number of pups from this study, based on follicle number, total litter size, and number of 

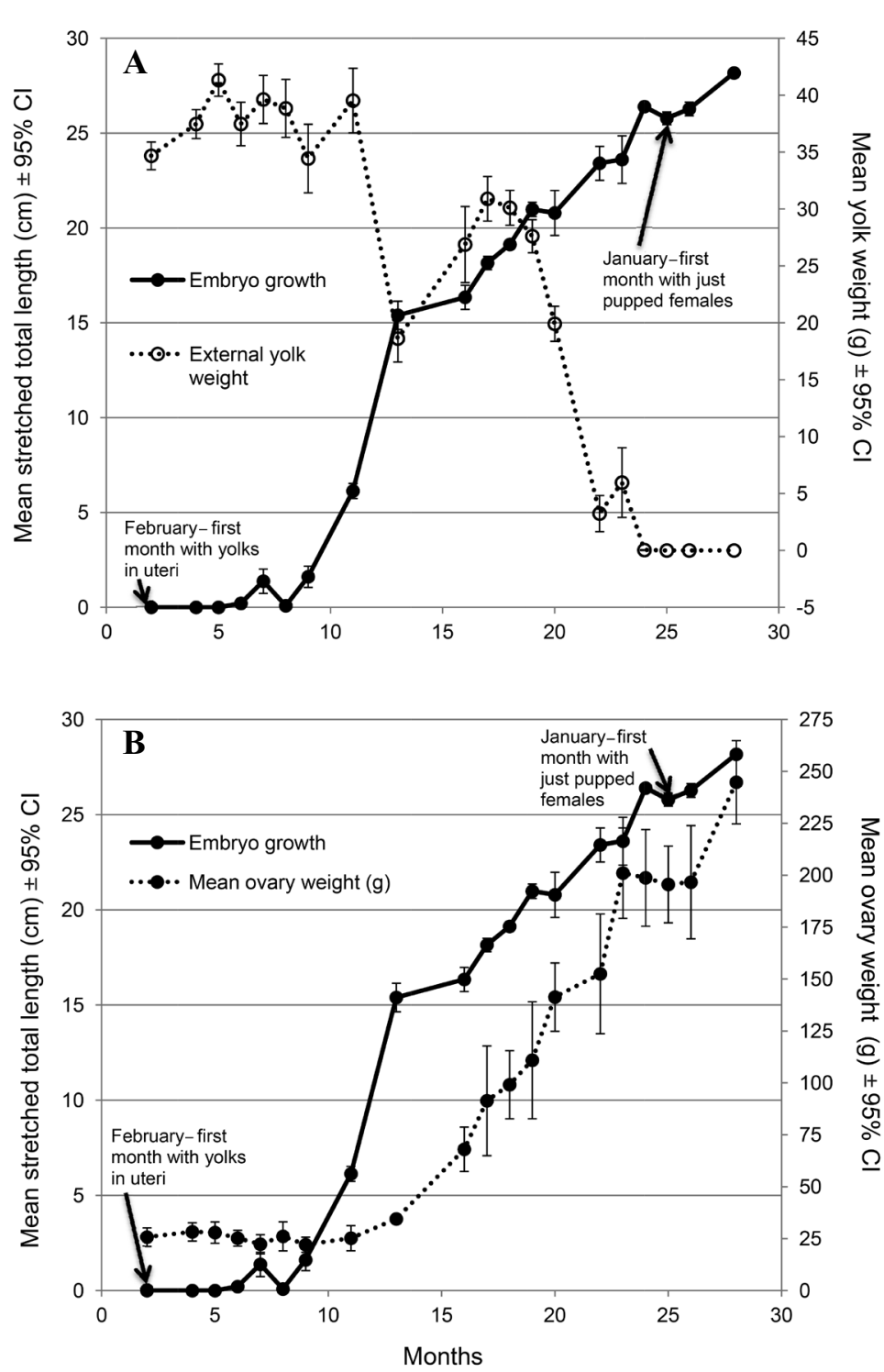

Figure 5

Growth of embryos and (A) external yolk and (B) ovary weight through the 2-year gestation period of spiny dogfish (Squalus acanthias) sampled off southern New England and New Jersey in 20132015. Month 1 corresponds to January of the first year of the cycle. For months 2-6, data are from just fertilized embryos from February to June 2014 and are included to exemplify the typical first 6 months of growth. Months 7-23 correspond to monthly samples collected from July 2013 to April 2015. Error bars indicate 95\% confidence intervals (CIs).

only free-living embryos, was similar although the estimates based on oocytes were higher than those based on embryo counts. Jensen (1965) noted premature delivery of near-term pups directly after collection aboard fishing vessels and speculated that this phenomenon is widespread, but is not often reported. He stated that the premature pupping was never ex- cessive and therefore reported estimates of fecundity are still appropriate (Jensen, 1965). The fecundity estimate based on oocytes (5.3) is the highest of the 3 estimates and suggests that not all oocytes are successfully fertilized. Nammack et al. (1985) also found higher numbers of oocytes than embryos and found evidence of ovulation failure. The estimate of fecundity per female from the number of free-living embryos only (4.3) is slightly lower than the estimate from the number of total embryos (4.5) suggesting the potential influence of premature pupping on the estimate of freeliving embryos. Because the total estimate eliminates some of the decrease caused by premature pupping, this is the more accurate estimate of fecundity of spiny dogfish. The estimate of free-living embryos from this study falls within the range of other studies in the WNA (Templeman, 1944 [mean: 3.7]; Nammack et al., 1985 [mean: 6.6]; Sosebee, 2005 [mean: 4.4]; Campana et al., 2009 [mean: 4.7]).

Nammack et al. (1985) suggested a possible compensatory increase in the number of pups (overall and by size class) was due to a reduction in stock biomass but noted that the increase could simply be due to differences in sampling locations. Silva (1993) found a negative correlation between spiny dogfish fecundity by size class and abundance estimates from the WNA through 1991 (including data from Templeman [1944] and Nammack et al. [1985]). Additionally, significant correlations for the 80-84, 85-89, and 90-94 cm STL size classes suggest that spiny dogfish fecundity is density dependent (Silva, 1993). Sosebee (2005) reported that the reduction in overall mean fecundity in her study in comparison with results from the Nammack et al. (1985) study is likely due to a truncation of the population size structure resulting from the size selective nature of the fishery. There was also no evidence of density-dependent changes in mean fecundity by maternal size class in the study by Sosebee (2005). At that time, reproductive spiny dogfish were no longer declining in abundance, which may have negated any changes that would result from density dependence (Sosebee, 2005). Our overall mean fecundity based on free-living embryos is similar to that of Sosebee (2005), but data by size class in all length groups showed a decrease in mean fecundity from Sosebee (2005) and more notable drops in the larger size classes. Because status updates (Rago and Sosebee ${ }^{2,3}$ ) indicate that female spawning stock biomass has been rebuilding since the time of the study 
by Sosebee (2005) was completed, it is possible that the reductions in fecundity reflect environmentally controlled, density-dependent reproduction.

This study was a regionally based study designed to determine whether spiny dogfish in the waters off SNE between Massachusetts and Rhode Island follow the pattern of those from the Gulf of Maine and other northwest Atlantic regions. Our sampling regime allowed for a more detailed examination of gestation than that which has previously been accomplished. Although this study was designed to be regional, we cannot ignore the fact that these fish migrate between the Gulf of Maine, SNE, and the mid-Atlantic (Rulifson et al.8; Sulikowski et al., 2010). In fact, some recent satellite tagging data indicate significant regional movements (Carlson et al., 2014). Spiny dogfish located off SNE throughout the year may include components of both resident and migrating populations. This is in line with Campana et al. (2009), who also found resident and migratory populations in their study area off the coast of eastern Canada.

\section{Acknowledgments}

We thank all the commercial fishermen who collected the samples for this project. We also could not have completed this project without help from NMFS Cooperative Research Program, particularly: K. Burchard, C. Alexander, B. Gervelis, E. Marchetti, and C. Sarro. We also appreciate the help of C. Flight and S. Chen in recording data. R. Guilmette and J. Tully were essential for sample removal. We would also like to thank R. $\mathrm{McBride}$ and K. Sosebee for their thoughtful comments on our draft.

\section{Literature cited}

Avsar, D.

2001. Age, growth, reproduction and feeding of the spur$\operatorname{dog}$ (Squalus acanthias Linnaeus, 1758) in the southeastern Black Sea. Est. Coast. Shelf Sci. 52:269-278. Article

Bigelow, H. B., and W. C. Schroeder. 1953. Fishes of the Gulf of Maine. Fish. Bull. 53:1-577. Bubley, W.

2010. Updated life history and population structure assessment of spiny dogfish, Squalus acanthias, in the Gulf of Maine. Ph.D. diss, 144 p. Univ. New Hampshire, Durham, NH.

Bubley, W. J., J. A. Sulikowski, D. M. Koester, and P. C. W. Tsang.

2013. Using a multi-parameter approach to reassess maturity of spiny dogfish, Squalus acanthias, following

\footnotetext{
${ }^{8}$ Rulifson, R. A., T. M. Moore, and C. S. Hickman. 2002. Biological characterization of the North Carolina spiny dogfish (Squalus acanthias) fishery. Report for Project No. 97FEG28. [Available from Fisheries Resource Grant Program, North Carolina Sea Grant, P.O. Box 8605, NCSU, Raleigh, NC 27695-8605.]
}

increased fishing pressure in the Western North Atlantic. Fish. Res. 147: 202-212. Article

Campana, S. E., C. Jones, G. A. McFarlane, and S. Myklevoll. 2006. Bomb dating and age validation using the spines of spiny dogfish (Squalus acanthias). Environ. Biol. Fish. 77:327-336. Article

Campana, S. E., W. Joyce, and D. W. Kulka.

2009. Growth and reproduction of spiny dogfish off the eastern coast of Canada, including inferences on stock structure. In Biology and management of dogfish sharks (V. F. Gallucci, G. A. McFarlane, and G. G. Bargmann, eds.), p. 195-207. Am. Fish. Soc., Bethesda, MD.

Capapé, C., and C. Reynaud.

2011. Maturity, reproductive cycle and fecundity of the spiny dogfish Squalus acanthias (Chondrichthyes: Squalidae) off the Languedocian coast (southern France, northern Mediterranean). J. Mar. Biol. Assoc. U.K. 91:1627-1635. Article

Carlson, A. E., E. R. Hoffmayer, C. A. Tribuzio, and J. A. Sulikowski.

2014. The use of satellite tags to redefine movement patterns of spiny dogfish (Squalus acanthias) along the U.S. East Coast: implications for fisheries management. PLoS ONE 9(7):e103384. Article

Chatzispyrou, A., and P. Megalofonou.

2005. Sexual maturity, fecundity and embryonic development of the spiny dogfish, Squalus acanthias, in the eastern Mediterranean Sea. J. Mar. Biol. Assoc. U.K. 85:1155-1161.

Collette, B. B., and G. Klein-MacPhee (eds.).

2002. Bigelow and Schroeder's fishes of the Gulf of Maine, $3^{\text {rd }}$ ed., 748 p. Smithsonian Institution Press, Washington, DC.

Di Giacomo, E. E., M. R. Perier, and M. Coller.

2009. Reproduction of spiny dogfish in San Matias Gulf, Patagonia (Argentina). In Biology and management of dogfish sharks (V. F. Gallucci, G. A. McFarlane, and G. G. Bargmann, eds.), p. 209-215. Am. Fish. Soc., Bethesda, MD.

Driggers, W. B., III, and E. R. Hoffmayer.

2009. Variability in the reproductive cycle of finetooth sharks, Carcarhinus isodon, in the northern Gulf of Mexico. Copeia 2009:390-393.

Ebert, D. A., W. T. White, K. J. Goldman, L. J. V. Compagno, T. S. Daly-Engel, and R. D. Ward.

2010. Resurrection and redescription of Squalus suckleyi (Girard, 1854) from the North Pacific, with comments on the Squalus acanthias subgroup (Squaliformes: Squalidae). Zootaxa 2612:22-40.

Ford, E.

1921. A contribution to our knowledge of the life-histories of the dogfishes landed at Plymouth. J. Mar. Biol. Assoc. U.K. 12:468-505. Article

Gračan, R., B. Lazar, I. Posavec, G. Gregorović, and G. Lacković.

2013. Maturation, fecundity and reproductive cycle of spiny dogfish, Squalus acanthias, in the Adriatic Sea. Mar. Biol. Res. 9:198-207. Article

Hamlett, W. C. and T. J. Koob.

1999. Female reproductive system. In Sharks, skates, and rays: the biology of elasmobranch fishes (W. C. Hamlett, ed.), p. 398-444. Johns Hopkins Univ. Press, Baltimore, MD. 
Hanchet, S.

1988. Reproductive biology of Squalus acanthias from the east coast, South Island, New Zealand. N. Z. J. Mar. Freshw. Res. 22:537-549. Article

Henderson, A. C., K. Flannery, and J. Dunne.

2002. Growth and reproduction in spiny dogfish Squalus acanthias L. (Elasmobranchii: Squalidae), from the west coast of Ireland. Sarsia 87:350-361. Article

Hisaw, F. L., and A. Albert.

1947. Observations on the reproduction of the spiny dogfish, Squalus acanthias. Biol. Bull. 92:187-199.

Hoffmayer, E. R., W. B. Driggers III, L. M. Jones, J. M. Hendon, and J. A. Sulikowski.

2013. Variability in the reproductive biology of the Atlantic sharpnose shark in the Gulf of Mexico. Mar. Coast. Fish. 5:139-151. Article

Jensen, A. C.

1965. Life history of the spiny dogfish. Fish. Bull. 65:527-554

Jones, B. C., and G. H. Geen.

1977. Reproduction and embryonic development of spiny dogfish (Squalus acanthias) in the Strait of Georgia, British Columbia. J. Fish. Res. Board Can. 34:12861292. Article

Kaganovskaia, S. M.

1937. On the commercial biology of Squalus acanthias. Izv. Tikhookean. Nauch.-Issled. Inst. Ryb. Khoz. Okeanogr. 10:105-115.

Ketchen, K. S.

1972. Size at maturity, fecundity, and embryonic growth of the spiny dogfish (Squalus acanthias) in British Columbia waters. J. Fish. Res. Board Can. 29:1717-1723. Article

Lombardi-Carlson, L. A., E. Cortés, G. R. Parsons, and C. A. Manire.

2003. Latitudinal variation in life-history traits of bonnethead sharks, Sphyrna tiburo, (Carcharhiniformes: Sphyrnidae) from the eastern Gulf of Mexico. Mar. Freshw. Res. 54:875-883. Article

McMillan, D. G., and W. W. Morse.

1999. Essential fish habitat source document: spiny dogfish, Squalus acanthias, life history and habitat characteristics. NOAA Tech Memo NMFS-NE-150, 19 p.
Nammack, M. F., J. A. Musick, and J. A. Colvocoresses.

1985. Life history of spiny dogfish off the northeastern United States. Trans. Am. Fish. Soc. 114:367-376. Article

Rago, P. J., and K. A. Sosebee.

2009. The agony of recovery: scientific challenges of spiny dogfish recovery programs. In Biology and management of dogfish sharks (V. F. Gallucci, G. A. McFarlane, and G. G. Bargmann, eds.), p. 343-372. Am. Fish. Soc., Bethesda, MD.

Rochowski, B. E. A., T. I. Walker, and R. W. Day.

2015. Geographical variability in life-history traits of a midslope dogfish: the brier shark Deania calcea. J. Fish Biol. 87:728-747. Article

Silva, H. G. M.

1993. Population dynamics of spiny dogfish, Squalus acanthias, in the NW Atlantic. Ph.D. diss., 239 p. Univ. Mass. Amherst, Amherst, MA.

Sosebee, K. A.

2005. Are density-dependent effects on elasmobranch maturity possible? J. Northwest Atl. Fish. Sci. 35:115-124.

Sulikowski, J. A., B. Galuardi, W. Bubley, N. B. Furey, W. B. Driggers III, G. W. Ingram Jr., and P. C. W. Tsang.

2010. Use of satellite tags to reveal the movements of spiny dogfish Squalus acanthias in the western North Atlantic Ocean. Mar. Ecol. Prog. Ser. 418:249-254. Article

Sulikowski, J. A., B. K. Prohaska, A. E. Carlson, A. M. Cicia, C. T. Brown, and A. C. Morgan.

2013. Observation of neonate spiny dogfish, Squalus acanthias, in southern New England: a first account of a potential pupping ground in the northwestern Atlantic. Fish. Res. 137:59-62. Article

Taylor, S. M., A. V. Harry, and M. B. Bennett.

2016. Living on the edge: latitudinal variations in the reproductive biology of two coastal species of sharks. J. Fish Biol. 89:2399-2418. Article

Templeman, W.

1944. The life-history of the spiny dogfish (Squalus acanthias) and the vitamin A values of dogfish liver oil. Dep. Nat. Resour. the Newfoundland, Res. Bull.15, 102 p.

Yamamoto, T., and O. Kibezaki.

1950. Studies on the spiny dogfish Squalus acanthias (L.) on the development and maturity of genital glands and growth. Hokkaido Reg. Fish. Resour. Res. Rep. 3:531-538. 